(2) Open Access Full Text Article

\title{
External Validation of the S.T.O.N.E. Score in Predicting Stone-Free Status After Rigid Ureteroscopic Lithotripsy
}

This article was published in the following Dove Press journal: Research and Reports in Urology

\section{Noppavut Sirirak \\ Premsant Sangkum \\ Yada Phengsalae \\ Wisoot Kongchareonsombat (D) \\ Charoen Leenanupunth \\ Wattanachai \\ Ratanapornsompong \\ Chinnakhet Ketsuwan (ID)}

Division of Urology, Department of Surgery, Faculty of Medicine Ramathibodi Hospital, Mahidol University, Bangkok, 10400, Thailand
Correspondence: Chinnakhet Ketsuwan

Tel +66-2-20II 536

Fax +66-2-2794704

Email chinnakhet.ket@mahidol.ac.th
Background: The Size, Topography, Obstruction, Number, and Evaluation of Hounsfield units (S.T.O.N.E.) scoring system has been proposed as a novel prognostic surgical classification for urolithiasis in predicting success rate and complications.

Objective: We carried out an externally validated S.T.O.N.E. score on rigid ureteroscopic lithotripsy (rURS).

Materials and Methods: The data of patients who had undergone rURS between 2012 and 2019 at a tertiary referral center were audited retrospectively. The S.T.O.N.E. score was calculated based on factors determined through preoperative computed tomography images and was analyzed in association with stone-free rate (SFR), operating time, surgical complications, and length of stay (LOS).

Results: A total of 155 patients were included in the study with a median stone size of $10 \mathrm{~mm}(7-12)$ and a median S.T.O.N.E. score of 9 (8-10). The overall SFR was $89.68 \%$. SFRs were $100.0 \%, 97.83 \%$, and $77.42 \%$ in low (5), moderate (6-9), and high (10-13) score groups, respectively. The S.T.O.N.E. score $(p=0.002)$ and stone size $(p=0.037)$ were predictive factors for SFR in multivariate analysis. Moreover, there was a significant correlation between the S.T.O.N.E. score and operative time, LOS, and presence of complications ( $r=0.22, p=0.006 ; r=0.30, p<0.001$; and $r=0.27, p<0.001$, respectively). The area under the curve of the receiving operator characteristics' curve for the S.T.O.N.E. score was 0.815 .

Conclusion: The S.T.O.N.E. scoring system is simple and effective in predicting postoperative outcomes; therefore, this score would be a valuable tool in clinical planning for every patient who undergoes rURS.

Keywords: ureteroscopy, S.T.O.N.E. score, stone-free rate

\section{Introductions}

Urolithiasis is one of the most prevalent urological problems worldwide, with rates ranging from $1 \%$ to $5 \%$ in Asia and $7 \%$ to $13 \%$ in North America. ${ }^{1}$ Because of high temperatures and excessive sun exposure, the incidence of urolithiasis is much higher in tropical areas, such as Thailand. ${ }^{2}$ According to the European Association of Urology Guidelines, ${ }^{3}$ both extracorporeal shockwave lithotripsy (ESWL) and ureteroscopy (URS) are good options for the management of ureteric calculi due to their high stone-free rate (SFR). However, to achieve complete clearance, ESWL necessitates multiple repeat sessions and extensive follow-up, increasing the total duration of the therapy. For obese patients $\left(\mathrm{BMI}>30 \mathrm{~kg} / \mathrm{m}^{2}\right)$ or patients with larger 
stones, URS is more reliable in obtaining earlier SFR but has the potential risk of causing serious complications. Thus, a tool for predicting positive and negative outcomes after surgery is an essential component for patient management.

At the present time, there are several predictive models that characterize the complexity of nephrolithiasis and predict postoperative results after percutaneous nephrolithotomy (PCNL), namely Guy's Stone Score, the Clinical Research Office of the Endourological Society (CROES) nephrolithometric nomogram, the Size, Topography, Obstruction, Number, and Evaluation of Hounsfield units (S.T.O.N.E.) Nephrolithometry score, and the Seoul National University Renal Stone Complexity scoring system. $^{4-8}$ However, the S.T.O.N.E. score is the only model that assesses the location of ureteric calculi. It also helps forecast the SFR for patients who require URS. To our knowledge, no studies have been performed to confirm its external validity.

We hypothesized that the S.T.O.N.E. scoring system would be an excellent predictor for the success of URS. Consequently, we externally validated the S.T.O.N. E. score using an independent external cohort.

\section{Materials and Methods}

The present study complied with the principles outlined in the Helsinki Declaration. After acquiring ethical approval from the Institutional Review Board of the Faculty of Medicine at Ramathibodi Hospital (COA. MURA2019/ 874), we retrospectively reviewed the medical records of patients who had undergone rigid ureteroscopic lithotripsy (rURS) for ureteral calculi by highly experienced endourologists in a tertiary referral center. Consent for chart review was not required by the ethical committee due to the retrospective nature of the study. All data were encrypted and kept confidential.

A total of 155 consecutive procedures were collected. The inclusion criteria for treatment were patients who had undergone rURS between January 2012 and July 2019. The exclusions were as follows: patients under the age of 18 , patients lacking a preoperative computed tomography (CT) scan, patients who underwent URS without lithotripsy, and patients whose data were deficient. The imaging data and S.T.O.N.E. score were determined for each patient on a CT scan by two urology residents, who made one estimation per patient. Stone size was described as the maximum diameter of the stone in any plane. Patient characteristics and all surgical data were collected, including age, sex, body mass index (BMI), American Society of Anesthesiology classification, stone size, stone side, complete blood count, serum biochemistry, coagulation tests, urinalysis, and operative report. The perioperative analysis consisted of targeted SFR, operative time, length of stay (LOS), and postoperative complications using the modified Clavien classification system. ${ }^{9}$ The primary outcome of this measurement was stone-free status in the postoperative period. A successful rURS was determined by the clinical status of stone free, which was defined as no evidence of a stone or clinically insignificant residual fragment stones less than $2 \mathrm{~mm}$, as demonstrated by repeated postoperative CT scans or by meticulous endoscopic inspection and simultaneous fluoroscopy with the capability for powerful magnification imaging. ${ }^{10}$

The S.T.O.N.E. score consists of five parameters. The point values for size of stone (S) are 1 point for stones less than $5 \mathrm{~mm}, 2$ points for stones equal to or more than $5 \mathrm{~mm}$ but less than $10 \mathrm{~mm}$, and 3 points for stones more than $10 \mathrm{~mm}$. For topography or location of stone $(\mathrm{T})$, the values are 1 point for distal and mid-ureteric stones, 2 points for proximal ureter, mid-pole, and upper pole stones, and 3 points for lower pole stones. Obstruction $(\mathrm{O})$ is evaluated by degree of hydronephrosis: 1 point for no hydronephrosis, 2 points for mild to moderate hydronephrosis (grade 1-2), and 3 points for severe hydronephrosis (grade 3-4). Number of stones $(\mathrm{N})$ is represented by 1 point for 1 stone, 2 points for 2 stones, and 3 points for 3 stones or more. Evaluation (E) of the Hounsfield unit (HU) is 1 point for less than $750 \mathrm{HU}, 2$ points for between 750 and $1000 \mathrm{HU}$, and 3 points for equal to or more than $1000 \mathrm{HU}$. The grades are then summed to give a final S.T.O.N.E. score ( 5 to 15 points).

\section{Surgical Technique}

For all patients undergoing rURS, the healthcare providers followed a standard approach. After routinely acquiring signed operative informed consent forms from all individuals, rURS was performed under either general or regional anesthesia, depending on the patient. A single dose of antibiotic prophylaxis (typically third-generation cephalosporin) was given intravenously when the patient started anesthesia and was continued for 24 to 48 hours.

Patients were placed in the dorsal lithotomy position. The procedure started initially with a rigid cystoscopy to visualize the bladder and identify the ureteric orifice, followed by the introduction of a guidewire through the ureteral orifice up to the kidney. A rigid ureteroscopy (8Fr, Karl Storz, Tuttlingen, Germany) was conducted in 
all cases. During the lithotripsy process, a Dornier Medilas H20 holmium YAG laser (200 or 365 micron fibers) or Swiss LithoClast ${ }^{\circledR}$ Pneumatic Lithotriptor (Electro Medical Systems, Le Sentier, Switzerland) was used. Residual stone fragments were either actively removed or left without retrieval, depending on their size. At the end of the procedure, an open-end ureteric catheter or a double-J stent was retrogradely inserted according to the patient's clinical condition and the surgeon's determination.

\section{Statistical Analysis}

The statistical analysis was done on STATA version 14.1 (STATA Corp., TX, USA). Descriptive variables were presented as medians with interquartile ranges (IQRs) or numbers and percentages. Associations between continuous variables were compared using the Mann-Whitney $U$-test. Correlations between continuous variables were assessed using the Pearson correlation coefficient. Categorical variables were compared using a chi-square test. A $p$-value less than 0.05 was considered statistically significant. Significant predictors of SFR were analyzed by univariate and multivariate logistic regression analyses. A receiver operator characteristic (ROC) curve was performed to assess the accuracy of preoperative predictors of stone-free status.

\section{Results}

From January 2012 to July 2019, 165 patients underwent rURS. Of these, 10 subjects were excluded from the present study. A total of 155 patients met the inclusion criteria and were enrolled in this validation cohort, including 79 (50.9\%) males and 76 (49.1\%) females. The median age of the patients was 59 years $(52-65)$ with a median BMI of $26.5 \mathrm{~kg} / \mathrm{m}^{2}$ (23.4-29.5). The median stone diameter was $10 \mathrm{~mm}$ (7-12), and the median stone density was 835.4 HU (528.5-1037.1). The median S.T.O.N.E. score of the present study was $9(8-10)$.

\section{Stone-Free Status}

The overall SFR in our cohort was $89.68 \%$. The patient demographics and stone characteristics were compared between the stone-free and non-stone-free groups and are shown in Table 1. In univariate logistic regression analysis, stone size (9 vs.13.5, $p<0.001$ ), S.T.O.N.E. score (9 vs 10, $p<0.001$ ), and operative time ( 75 vs $87.5, p=0.041$ ) were significant predictors for SFR. No statistical differences were found for the location of calculi, presence of hydronephrosis, stone number, and stone density $(p=0.089,0.161,0.171$, and 0.819 , respectively). Multivariate logistic regression analysis indicated that only the S.T.O.N.E. score and stone diameter were significant predictors for SFR postoperatively (Table 2).

Figure 1 illustrates SFRs according to S.T.O.N. E. scores. The SFR progressively declined from 100.0\% to $33.3 \%$ as the S.T.O.N.E score increased from 5 to 13 . When the study subjects were categorized into three subgroups, there were $1(0.65 \%), 92(59.35 \%)$, and 62 $(40.00 \%)$ subjects in low (5), moderate (6-9), and high (10-13) score subgroups, respectively. SFRs were 100\%, $97.83 \%$, and $77.42 \%$ in the low, moderate, and high score groups, respectively, and there were significant differences among the groups $(p<0.001)$. Since stone size and S.T.O. N.E. score are the only preoperative predictors of SFR in multivariate analysis, ROC curves were drawn to compare their accuracies in predicting SFR (Figure 2). Both determinants had comparable accuracies with an area under the curve (AUC) of 0.774 and 0.815 for stone size and S.T.O. N.E. scoring system, respectively.

\section{Perioperative Data}

Postoperative complications were observed in six patients $(3.87 \%)$, including fever $(n=3)$ and sepsis $(n=3)$. The median operation time was $75 \mathrm{~min}(45-100)$, and the median hospitalization time was four days (3-4). Moreover, in terms of correlation between the S.T.O.N.E. score and perioperative outcomes, we found a significant correlation between the $\mathrm{S}$. T.O.N.E. score and operative time, LOS, and presence of complications $(\mathrm{r}=0.22, \mathrm{p}=0.006 ; \mathrm{r}=0.30, \mathrm{p}<0.001$; and $\mathrm{r}=0.27, \mathrm{p}<0.001$, respectively) (Table 3 ).

\section{Discussion}

Today, surgical management of urolithiasis is usually a minimally invasive procedure, with a preference for endourologic techniques. Active stone removal modalities from the kidney or ureter usually consists of ESWL, PCNL, and URS. Various stone factors influence the achievement of stone-free status, including stone hardness, location, number, and size. Moreover, the incidence of postoperative surgical complications can be associated with multiple variables, such as complexity of the procedure, patient characteristics, and the surgeon's case volume. ${ }^{11-14}$ Scoring systems or nomograms were developed using the aforementioned variables in order to assess procedural complexity and predict outcomes, which helps with risk assessment for patient counseling, surgery 
Table I Demographics and Perioperative Parameters

\begin{tabular}{|c|c|c|c|c|}
\hline Variable & $\begin{array}{c}\text { Total } \\
(n=155)\end{array}$ & $\begin{array}{c}\text { Stone Free } \\
(n=139)\end{array}$ & $\begin{array}{l}\text { Not Stone Free } \\
\qquad(n=16)\end{array}$ & p-value \\
\hline Age (years): median (IQR) & $\begin{array}{c}59 \\
(52 \text { to } 65)\end{array}$ & $\begin{array}{c}59 \\
(52 \text { to } 64)\end{array}$ & $\begin{array}{c}59.5 \\
\text { (53 to } 66.5)\end{array}$ & 0.748 \\
\hline $\begin{array}{l}\text { Gender: n (\%) } \\
\text { Female } \\
\text { Male }\end{array}$ & $\begin{array}{l}76(49) \\
79(5 I)\end{array}$ & $\begin{array}{l}65(47) \\
74(53)\end{array}$ & $\begin{array}{l}\text { II (69) } \\
5(31)\end{array}$ & 0.096 \\
\hline BMI $\left(\mathrm{kg} / \mathrm{m}^{2}\right)$ : median (IQR) & $\begin{array}{c}26.5 \\
\text { (23.4 to } 29.5)\end{array}$ & $\begin{array}{c}26.8 \\
\text { (23.5 to } 29.7)\end{array}$ & $\begin{array}{c}24.4 \\
\text { (19.9 to } 27.5)\end{array}$ & 0.117 \\
\hline $\begin{array}{l}\text { Stone laterality: } \mathrm{n}(\%) \\
\text { Right } \\
\text { Left }\end{array}$ & $\begin{array}{l}80(52) \\
75(48)\end{array}$ & $\begin{array}{l}69(50) \\
70(50)\end{array}$ & $\begin{array}{l}11(69) \\
5(31)\end{array}$ & 0.147 \\
\hline Stone size $\left(\mathrm{mm}^{2}\right)$ : median (IQR) & $\begin{array}{c}10 \\
(7 \text { to } 12)\end{array}$ & $\begin{array}{c}9 \\
(7 \text { to } 10)\end{array}$ & $\begin{array}{c}13.5 \\
(10 \text { to } 15.5)\end{array}$ & $<0.00 I^{*}$ \\
\hline $\begin{array}{l}\text { Stone location: n (\%) } \\
\text { Distal ureter } \\
\text { Proximal ureter }\end{array}$ & $\begin{array}{l}89(57) \\
66(43)\end{array}$ & $\begin{array}{l}83(60) \\
56(40)\end{array}$ & $\begin{array}{c}6(38) \\
10(62)\end{array}$ & 0.089 \\
\hline Presence of hydronephrosis: $n$ (\%) & $125(8 \mid)$ & $110(79)$ & $15(94)$ & 0.161 \\
\hline Stone number: median (IQR) & I (I to I) & I (I to I) & I (I to 2$)$ & 0.171 \\
\hline $\begin{array}{l}\text { Stone density (Hounsfield unit): } \\
\text { median (IQR) }\end{array}$ & $\begin{array}{c}835.4 \\
(528.5 \text { to } 1037.1)\end{array}$ & $\begin{array}{c}826.3 \\
(529 \text { to } 1021.4)\end{array}$ & $\begin{array}{c}869.9 \\
\text { (521.9 to } 1054.7)\end{array}$ & 0.819 \\
\hline $\begin{array}{l}\text { Lithotripsy: n (\%) } \\
\text { Pneumatic lithocast } \\
\text { Laser }\end{array}$ & $\begin{array}{l}21(14) \\
134(86)\end{array}$ & $\begin{array}{l}19(14) \\
120(86)\end{array}$ & $\begin{array}{l}2(12) \\
14(88)\end{array}$ & 0.897 \\
\hline $\begin{array}{l}\text { Operative time }(\mathrm{min}) \text { : } \\
\text { median (IQR) }\end{array}$ & $\begin{array}{c}75 \\
(45 \text { to } 100)\end{array}$ & $\begin{array}{c}75 \\
(45 \text { to } 90)\end{array}$ & $\begin{array}{c}87.5 \\
(62.5 \text { to } 117.5)\end{array}$ & $0.041^{*}$ \\
\hline Length of hospital stay (days): median (IQR) & 4 (3 to 4$)$ & 4 (3 to 4$)$ & $4(3.5$ to 7.5$)$ & 0.082 \\
\hline $\begin{array}{l}\text { Complications: n (\%) } \\
\text { Clavien I: Fever } \\
\text { Clavien IVa: Sepsis }\end{array}$ & $\begin{array}{l}3(50) \\
3(50)\end{array}$ & $\begin{array}{l}3(60) \\
2(40)\end{array}$ & $\begin{array}{l}0(0) \\
I(100)\end{array}$ & 0.273 \\
\hline $\begin{array}{l}\text { S.T.O.N.E. score: } \\
\text { median (IQR) }\end{array}$ & $9(8$ to 10$)$ & $9(8$ to 10$)$ & $10(9.5$ to 12$)$ & $<0.00 I^{*}$ \\
\hline
\end{tabular}

Note: *Statistically significant.

Abbreviations: BMI, body mass index; IQR, interquartile range.

Table 2 Univariate and Multivariate Analysis for Prediction of Stone-Free Status

\begin{tabular}{|c|c|c|c|c|c|c|}
\hline \multirow[t]{2}{*}{ Variable } & \multicolumn{3}{|c|}{ Univariate } & \multicolumn{3}{|c|}{ Multivariate } \\
\hline & OR & $95 \% \mathrm{Cl}$ & $p$-value & OR & $95 \% \mathrm{Cl}$ & $p$-value \\
\hline Stone size $\left(\mathrm{mm}^{2}\right)$ & 0.79 & 0.70 to 0.90 & $<0.001 *$ & 0.86 & 0.75 to 0.99 & $0.037^{*}$ \\
\hline Operative time ( $\mathrm{min}$ ) & 0.99 & 0.98 to 1.00 & $0.048^{*}$ & 0.99 & 0.98 to 1.01 & 0.711 \\
\hline S.T.O.N.E. score & 0.42 & 0.27 to 0.65 & $<0.001 *$ & 0.48 & 0.30 to 0.77 & $0.002 *$ \\
\hline
\end{tabular}

Note: *Statistically significant. 


\section{S.T.O.N.E. SCORE \\ Stone Free \\ Stone Not-Free}

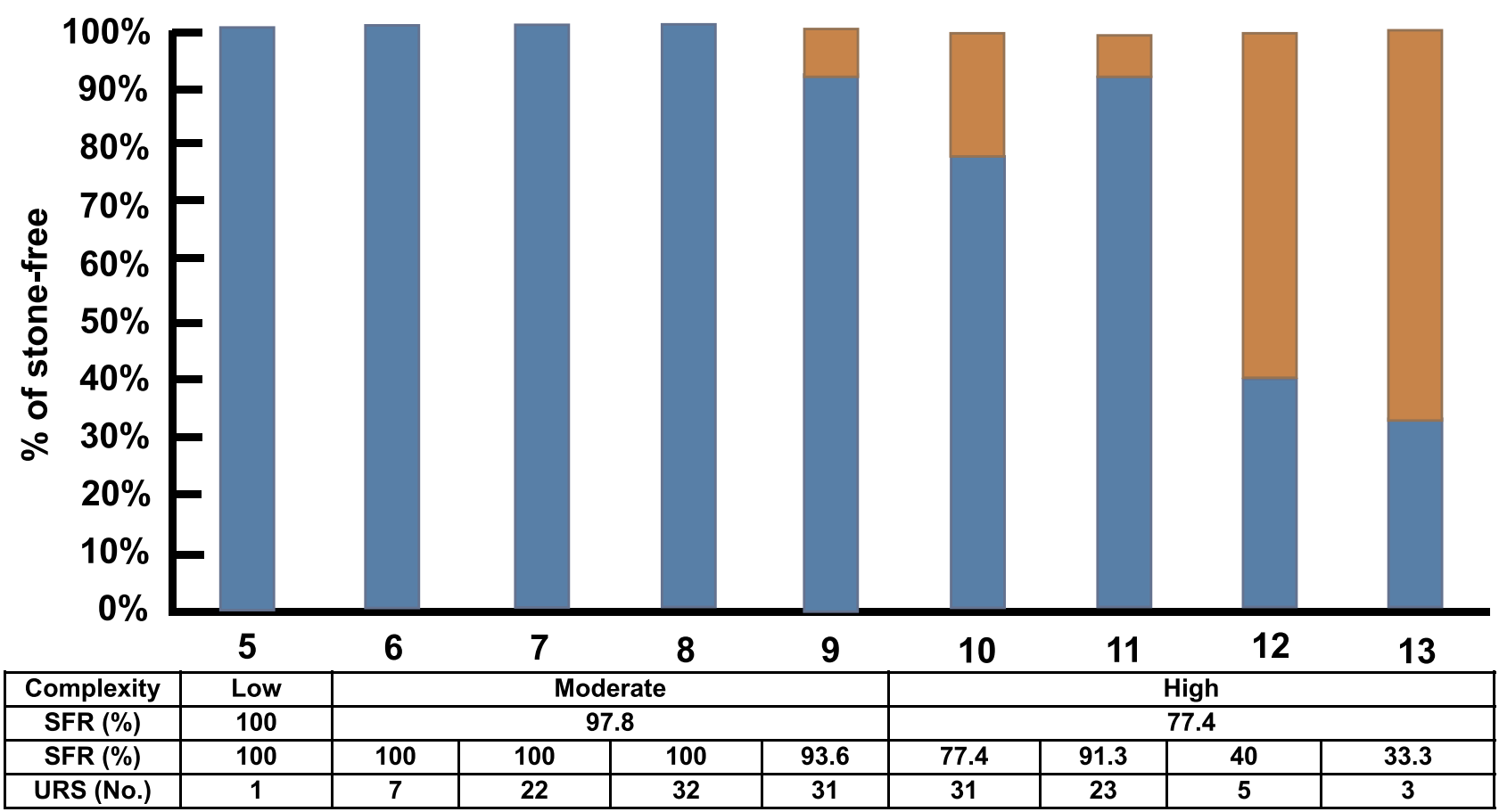

Figure I Effect of the S.T.O.N.E. score on stone-free status. Abbreviations: SFR, stone-free rate; URS, ureteroscopy.

A

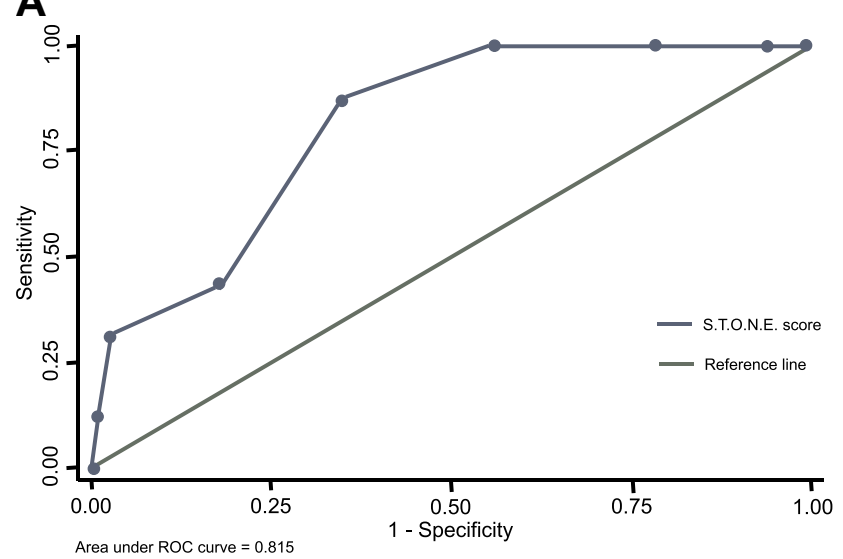

B

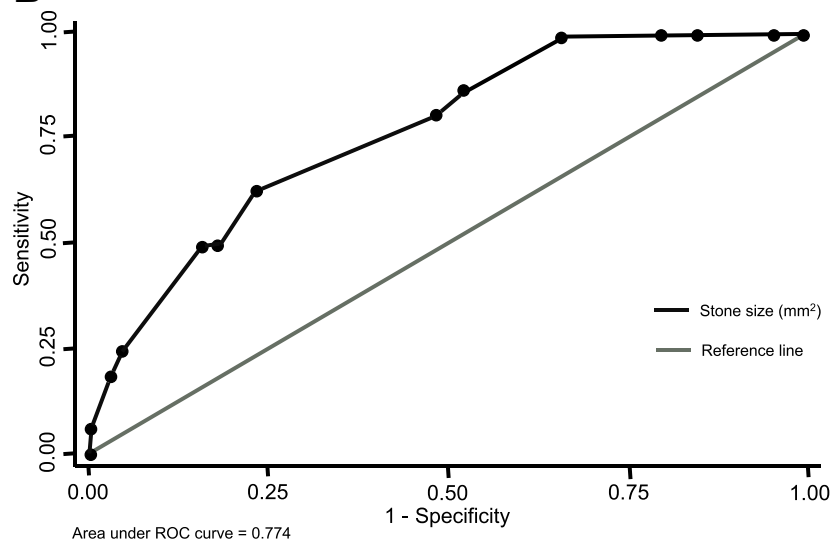

Figure 2 External validation of S.T.O.N.E. scoring system. (A) ROC curve of S.T.O.N.E. score. (B) ROC curve of stone size. Abbreviation: ROC, receiver operator characteristic.

preparation, prediction of the postoperative phase, and standardized reporting of the outcome measures.

Generally, a clinical scoring system should be easy to calculate and utilize rapidly, without significant training or specialized software. All the data used to evaluate the S.T. O.N.E. score was available promptly at the time of initial investigation by using non-contrast-enhanced CT images, the most common diagnostic imaging modality used in the evaluation of urolithiasis. Additionally, a good scoring system must be a precise predictor of outcome and be valid when applied outside the context of that study. The S.T.O.N.E. score fulfills these criteria as a clinical scoring system for ureteric calculi, and the present study's external validation of the S.T.O.N.E. scoring system confirms that 
Table 3 Correlation Between S.T.O.N.E. Score and Postoperative Outcomes

\begin{tabular}{|l|c|c|}
\hline \multirow{2}{*}{} & \multicolumn{2}{|c|}{ STONE Score } \\
\cline { 2 - 3 } & Rho & p-value \\
\hline Stone free status & -0.26 & 0.00 I $^{*}$ \\
Present of complication & 0.27 & $<0.00$ * $^{*}$ \\
Hospital stays & 0.30 & $<0.00 I^{*}$ \\
Operative time & 0.22 & $0.006^{*}$ \\
\hline
\end{tabular}

Note: *Statistically significant.

hypothesis. The present study demonstrates a significant correlation between the S.T.O.N.E. score and SFR, LOS, operative time, and postoperative complications $(p=0.001, p<0.001, p=0.006$, and $p<0.001$, respectively). These results are consistent with the original study by Molina et al that revealed a significant association between the S.T.O.N.E. score and SFR. As the S.T.O.N. E. score increased, the SFR dropped with a logical regression trend $(p<0.001) .{ }^{9}$ The mean S.T.O.N.E. score in this study is comparable to the mean S.T.O.N.E. score in the original study (9.06 vs 9.07). Overall SFR in the present study was $89.68 \%$, with $3.87 \%$ postoperative complications. These results are in line with the SFR reported by the CROES study, ${ }^{15}$ which included 8543 patients in 114 centers. They reported an SFR of $91.03 \%$ and a complication rate of $4.52 \%$.

In terms of the S.T.O.N.E. scoring system's accuracy, we had an AUC of 0.815 in predicting stone-free status post-URS. Likewise, Molina et $\mathrm{al}^{9}$ reported an AUC of 0.764 for the S.T.O.N.E. score. The univariate analysis in the present study demonstrated that in five variables of the S.T.O.N.E. scoring system, the only predictor that significantly negatively affected URS success was stone size $(p<$ 0.001 ). In addition, with an AUC of 0.774 , the predictive accuracy of the stone size for the SFR was high and comparable with the S.T.O.N.E. score. Therefore, the single stone size determinant may be as good as the S.T.O.N. E. scoring system in predicting stone-free status post-URS. Multiple previous studies confirmed the importance of stone size with respect to predicting the success of URS. Turunc et al ${ }^{16}$ studied the factors that affect the success of rURS for ureteral stones in pediatric patients, and they demonstrated a significant reverse correlation between stone size and SFR ( $p=0.007)$. In a multicenter study, Sen et $\mathrm{al}^{17}$ retrospectively evaluated, in a holistic manner, the predictive factors from URS involving upper ureteral stones. They found that stone area is one of the key risk factors affecting URS success $(\mathrm{OR}=0.993, p=0.002)$. For analysis of negative outcomes, Gunlusoy et $\mathrm{al}^{18}$ showed stone diameter was a significant parameter for the occurrence of complications (relative risk of 2 in multivariate analysis). However, we found conflicting evidence in a previous study that stone clearance is not affected by stone size. ${ }^{19}$

The remaining components of the S.T.O.N.E scoring system, namely tract length, obstruction, number, and stone essence, are still important factors and are higher in non-stone-free groups but do not reach statistical significance. In the present study, an SFR of approximately $84 \%$ for upper ureter stones is reported. However, the likelihood of operational success is greater when the stone is located more distally in the ureter, with an increased SFR of $93.3 \%$. This was confirmed by a previous meta-analysis of stone sizes larger than $10 \mathrm{~mm}$ treated with URS, in which distal stones had a higher clearance than proximal stones $(93 \%$ vs $79 \%){ }^{20}$ The poorer outcome is caused by the long distance and difficult access to the proximal ureter, as well as the easy upward migration of stone fragments to the kidney. Hydronephrosis and the presence of impacted stones are also mechanisms that reduce stone clearance. The grading of stone-induced hydronephrosis by imaging may be an indirect indicator of impacted ureteric calculi. Prolonged stone obstruction makes histological changes by increasing smooth muscle hypertrophy and collagen deposition, as well as producing inflammatory reactions, edema, and fibrosis at the ureteral wall. These are potential factors restricting stone retrieval and elevating the risk of ureteral wall injury. ${ }^{21,22}$ Seitz et al ${ }^{19}$ reported that the impaction of ureteric calculi was observed in $31.7 \%$ of cases and correlated significantly with SFR $(p<0.0001)$. Additionally, impacted ureteral stones exhibited a $2.3 \%$ rate of laserrelated complications as compared to a rate of $0.2 \%$ in nonimpacted stones.

Stone burden represents the volume of all calculi by merging both the size and number of stones. There are few studies about the association between the number of ureteric calculi and URS success. Kurahashi et $\mathrm{al}^{23}$ retrospectively analyzed the clinical outcomes in a total of 2129 consecutive patients who underwent URS for ureteric calculi in a single institution. Multivariate analysis identified the number of stones as an independent predictor for the entire removal of ureteral stones $(p<0.001)$. However, the results of the present validity assessment did not 
demonstrate a significant difference between SFRs and the number of ureteric calculi ( $p=0.171)$.

The Hounsfield unit density — or essence of the calculuson CT scanning can differentiate among various stone compositions, simplify the description of stone type, and contribute to the data regarding the possibility of stone fragmentation. During ESWL sessions, previous studies have indicated that stone attenuation values can affect treatment outcomes. ${ }^{24,25}$ However, the present study did not demonstrate a significant difference between the SFR and the density of the stone ( $p=$ 0.819 ) for URS procedures. Our results may be explained by the mechanism of intracorporeal lithotripsy in both devices, which had the ability to eradicate all types of stones regardless of composition. Holmium-YAG laser pulses produce a thermal effect by creating microscopic vaporization bubbles at the tip of the fiber, which develops a shock wave that fragments the stones or turns them into dust. Meanwhile, pneumatic lithotripsy breaks the stones by oscillatory movements of a metal rod directly against the stones. ${ }^{26}$

Recently, flexible URS is increasingly used as standard treatment for patients with midsized nephrolithiasis and proximal ureteral calculi that are difficult to reach using rURS. Some previous studies proved the predictive value of the S.T.O.N.E. score for SFR following retrograde intrarenal surgery. Richard et $\mathrm{al}^{27}$ retrospectively reviewed 800 flexible URS procedures and demonstrated that the AUC for the ROC of the S.T.O.N.E score exhibited an intermediate level of prediction; 0.644 [95\% CI: 0.609-0.680]. Karsiyakali et $\mathrm{al}^{28}$ reported the stone burden and $\mathrm{S}$. T.O.N.E. score were statistically significantly higher in patients with a residual stone ( $\mathrm{p}<0.001$, for both). They also revealed an AUC for the ROC of the S.T.O.N.E. score was 0.837 , which is comparable with the present study.

This study has some limitations such as its retrospective nature and small sample size. In addition, the collection of data from different surgeons may have affected the reliability and validity of the study due to differences in personal techniques. However, all urologists who performed URS in the present study were high-volume endourologists, so we believe that this factor influences the results minimally. Furthermore, the present study did not include stone composition which may influence the SFR. However, to the best of our knowledge, this is the first study to validate the S.T.O. N.E. score for the rURS procedure.

\section{Conclusion}

In conclusion, the present study validated the predictive value of the S.T.O.N.E. score for SFR after rURS in an independent cohort. It also correlated with operative duration, hospitalization, and adverse events. Thus, the S.T.O. N.E. scoring system is a valuable tool in clinical planning for every patient undergoing rURS, due to its simple calculation and effectiveness.

\section{Acknowledgments}

We would like to express our thanks to all involved in this study, as well as the section of Clinical Epidemiology and Biostatistics, Faculty of Medicine, Ramathibodi Hospital, for their support of the statistical analysis.

\section{Disclosure}

The authors declare that they have no competing interests in this work.

\section{References}

1. Sorokin I, Mamoulakis C, Miyazawa K, Rodgers A, Talati J, Lotan Y. Epidemiology of stone disease across the world. World $J$ Urol. 2017;35(9):1301-1320. doi:10.1007/s00345-017-2008-6

2. Tanthanuch M, Apiwatgaroon A, Pripatnanont C. Urinary tract calculi in southern Thailand. $J$ Med Assoc Thai. 2005;88(1):80-85.

3. Turk C, Neisius A, Petrik A, Seitz C, Tepeler A, Thomas K 2018. Urolithiasis. Available from: https://uroweb.org/wp-content/uploads/ EAU-Guidelines-onUrolithiasis_2017_10-05V2.pdf. Accessed December 2020.

4. Thomas K, Smith NC, Hegarty N, Glass JM. The Guy's stone score - grading the complexity of percutaneous nephrolithotomy procedures. Urology. 2011;78(2):277-281. doi:10.1016/j.urology.201 0.12 .026

5. Smith A, Averch TD, Shahrour K, et al. A nephrolithometric nomogram to predict treatment success of percutaneous nephrolithotomy. J Urol. 2013;190(1):149-156. doi:10.1016/j.juro.2013.01.047

6. Okhunov Z, Friedlander JI, George AK, et al. S.T.O.N. E. nephrolithometry: novel surgical classification system for kidney calculi. Urology. 2013;81(6):1154-1159. doi:10.1016/j.urology.20 12.10.083

7. Jeong CW, Jung JW, Cha WH, et al. Seoul National University renal stone complexity score for predicting stone-free rate after percutaneous nephrolithotomy. PLoS One. 2013;8(6):e65888. doi:10.1371/ journal.pone. 0065888

8. Ketsuwan C, Kijvikai K, Kongchareonsombat W, Sangkum P, Rongthong S, Leenanupunth C. A comprehensive comparison of Guy's stone score, CROES nomogram, S.T.O.N. E. nephrolithometry, and the Seoul renal stone complexity scoring system in predicting perioperative outcomes after percutaneous nephrolithotomy. J Med Assoc Thai. 2020;103:762-766.

9. Clavien PA, Barkun J, de Oliveira ML, et al. The Clavien-Dindo classification of surgical complications: five-year experience. Ann Surg. 2009;250(2):187-196. doi:10.1097/SLA.0b013e3181b13ca2

10. Molina WR, Kim FJ, Spendlove J, Pompeo AS, Sillau S, Sehrt DE. The S.T.O.N.E. score: a new assessment tool to predict stone free rates in ureteroscopy from pre-operative radiological features. Int Braz $j$ Urol. 2014;40(1):23-29. doi:10.1590/S1677-5538. IBJU.2014.01.04

11. Ketsuwan C, Kongchareonsombat W, Sangkum P, Kijvikai K, Sananmuang T, Leenanupunth C. Perioperative renal calculus factors affecting percutaneous nephrolithotomy outcomes. The Insight Urology. 2019;40(2):01-8. 
12. Al-Naimi A, Alobaidy A, Majzoub A, Ibrahim TAA. Evaluation of ureteroscopy outcome in a teaching hospital. Turk J Urol. 2016;42 (3):155-161. doi:10.5152/tud.2016.17037

13. Ketsuwan C, Pimpanit N, Phengsalae Y, Leenanupunth C, Kongchareonsombat W, Sangkum P. Peri-operative factors affecting blood transfusion requirements during PCNL: a retrospective non-randomized study. Res Rep Urol. 2020;12:279-285. doi:10.2147/RRU.S261888

14. Bloom J, Fox C, Fullerton S, Matthews G, Phillips J. Sepsis after elective ureteroscopy. Can J Urol. 2017;24(5):9017-9023.

15. Legemate JD, Wijnstok NJ, Matsuda T, et al. Characteristics and outcomes of ureteroscopic treatment in 2,650 patients with impacted ureteral stones. World J Urol. 2017;35(10):1497-1506. doi:10.1007/ s00345-017-2028-2

16. Turunc T, Kuzgunbay B, Gul U, et al. Factors affecting the success of ureteroscopy in management of ureteral stone diseases in children. J Endourol. 2010;24(8):1273-1277. doi:10.1089/end.2009.0476

17. Sen V, Irer B, Erbatu O, et al. Predictive factors of ureterorenoscopy outcomes in proximal ureteral stones: a multicenter study of Aegean Study Group of the Society of Urological Surgery. Urologia Internationalis. 2020;104(1-2):125-130. doi:10.1159/000504790

18. Gunlusoy B, Degirmenci T, Kozacioglu Z, et al. Factors affecting the complications of pneumatic lithotripsy for the treatment of ureteral stones with different localizations: a multivariate analysis of complications. Urol Int. 2013;91(3):357-362. doi:10.1159/ 000350243

19. Seitz C, Tanovic E, Kikic Z, Fajkovic H. Impact of stone size, location, composition, impaction, and hydronephrosis on the efficacy of holmium: YAG-laserureterolithotripsy. Eur Urol. 2007;52 (6):1751-1757. doi:10.1016/j.eururo.2007.04.029

20. Preminger GM, Tiselius H-G, Assimos DG, et al. 2007 Guideline for the management of ureteral calculi. Eur Urol. 2007;52(6):1610-1631. doi:10.1016/j.eururo.2007.09.039
21. Wu J, Zhu B, Ye C, et al. Five types of pathological ureters associated with operative difficulties during the procedure of rigid ureteroscopy. Curr Urol. 2011;5(4):202-208. doi:10.1159/000327479

22. Kinn AC, Lykkeskov-Andersen H. Impact on ureteral peristalsis in a stented ureter. An experimental study in the pig. Urol Res. 2002;30 (4):213-218. doi:10.1007/s00240-002-0258-1

23. Kurahashi T, Miyake H, Oka N, et al. Clinical outcome of ureteroscopic lithotripsy for 2,129 patients with ureteral stones. Urol Res. 2007;35(3):149-153. doi:10.1007/s00240-007-0095-3

24. Tarawneh E, Awad Z, Hani A, et al. Factors affecting urinary calculi treatment by extracorporeal shock wave lithotripsy. Saudi J Kidney Dis Transpl. 2010;21(4):660-665.

25. Abdelaziz H, Elabiad Y, Aderrouj I, et al. The usefulness of stone density and patient stoutness in predicting extracorporeal shock wave efficiency: results in a North African ethnic group. Can Urol Assoc J. 2014;8(7-8):E567-E569. doi:10.5489/cuaj.1849

26. Abedi AR, Razzaghi MR, Allameh F, Aliakbari F, Fallah-Karkan M, Ranjbar A. Pneumatic lithotripsy versus laser lithotripsy for ureteral stones. J Lasers Med Sci. 2018;9(4):233-236. doi:10.15171/ jlms.2018.42

27. Richard F, Marguin J, Frontczak A, et al. Evaluation and comparison of scoring systems for predicting stone-free status after flexible ureteroscopy for renal and ureteral stones. PLoS One. 2020;15(8): e0237068. doi:10.1371/journal.pone.0237068

28. Karsiyakali N, Karabay E, Erkan E, Kadihasanoglu M. Evaluation of Nephrolithometric Scoring Systems to Predict Outcomes of Retrograde Intrarenal Surgery. Urol J. 2020;17(4):352-357. doi:10.22037/uj.v0i0.5256
Research and Reports in Urology

\section{Publish your work in this journal}

Research and Reports in Urology is an international, peer-reviewed, open access journal publishing original research, reports, editorials, reviews and commentaries on all aspects of adult and pediatric urology in the clinic and laboratory including the following topics: Pathology, pathophysiology of urological disease; Investigation and

\section{Dovepress}

treatment of urological disease; Pharmacology of drugs used for the treatment of urological disease. The manuscript management system is completely online and includes a very quick and fair peer-review system, which is all easy to use. Visit http://www.dovepress.com/ testimonials.php to read real quotes from published authors. 